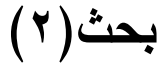

\section{أثر استخدام العجائن الورقيه على الخصائص التشكيليه للفيانس السيلكى فى مجال النحت الخزفى}

\author{
بحث مقدم من

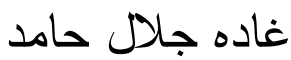 \\ الاستاذ المساعد- قسم النحت \\ كلية الفنون الجميله - جامعة الاسكندريه
}


من الطين كانت أفضل موروثات الحضاره الانسانيه التى بدأت بمعرفة النار واستمرت بين الوظيفه الدينيه والدنيويه تبحث عن المجهول لتترجم بصمة الخزاف وتحولها الى أنثكال و ألوان بالعديد من الخامات الخزفيه سواء الطبيعيه منها

كالطينات بانواعها ؛ او المخلقه والتى يعتبر الفيانس السيلكى أحد اهم انواعها و الخزف المعاصريجمع بين الاكتثاف والاختيار , مستهدفا التواصل مع الرؤى والتقنيات عن طريق البحث والتجريب فظهرت خزفيات بخصائص وقوانين تشكيليه مستحدثه طورت الكثيرا من القواعد التشكيليه للمجسم الخزفى ويعتبر الطين الورقى حاليا من أكثر الخامات الخزفيه المستخدمه فى مجال النحت والتشكيل الخزفى لما له من امكانات تشكيليه وخصائص طبيعيه ودور هام فى اظهار القيم الجماليه للتكوين الخزفى ؛ ومن خلال الدراسات السابقه للباحثه للفاينس السيلكى وكذلك من خلال التجارب الثخصيه وتجارب العديد من الخزافين المعاصرين فى مجال تشكيل الطين الورقى كان الهدف الرئيسى من البحث الذى يكمن فى امكانية المزج بين العجائن الورقيه وعجائن الفاينس السيلكى لتحسين خصائصها التنكيليه و لدحاولة التوسع تشكيليا مع وسائط تم

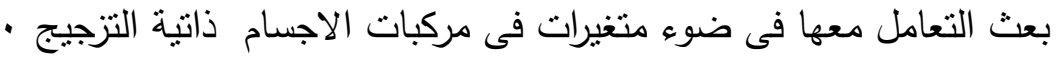

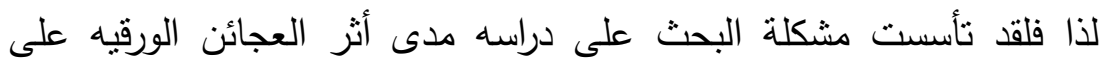
خصائص الفاينس السيلكى بهدف اضافه امكانيات نتكيليه بصعب تتفيذها فى العجائن التقليديه ؛ وذللك اعتمادا على المنهج التحليلى فى دراسه خصائص العينات المقترحه ؛ والمنهج المقارن فى رصد العلاقات والمقارنات بين النماذج المنفذه ؛ دراسه تجريبيه لمعرفة أثر الاكاسيد والصبغات الحراريه كملون على الجسم ؛ دراسه تطبيقيه لبعض العينات من العجائن للتعرف على خصائصها التشكيليه ونتائج تعرضها لانواع الحريق المختلفه وتتكامل هذه الدراسده من خلال نقاط بحثيه محده 
- أولا :- عرض نظرى تحليلى للخامات المستخدمه واهم المصطلحات المستخدمه - انيا :- اجراء تجارب على انواع مختلفه من المركبات للوصول الى افضل النماذج الصالحه للتشكيل - - ثالثا :- التعرف على الخصائص الميكانيكيه والتى تعرف علميا بقوى الاجهاد كالقابليه للضغط والالنواء للتعرف على مدى تحمل الكتله لنقل يعلوها ومدى قابليتها للانكماش او التشقق - رابعا :- التعرف على اثز الاكاسيد الملونه وظروف الحريق ونتائجه المباشره على الجسم واللون - خامسا :- لآنه لايمكن معرفة ما اذا كانت الخامه حيويه ومعبره الان بتجربه تطبيقيه تظهر فيها امكانيات الخامه التتكيليه ومعطياتها الجماليه فلقد قامت الباحثه بتنفيذ عدة اعمال كتطبيق عملى لمعرفة مدى لمه امكانياتها فى التشكيل وزيادة الحجم والسمك فى جدار العمل - سادسا :- عرض لاهم النتائج والتوصيات الخاصده بالدراسه

- سابعا :- المراجع المستخدمه وملخص البحث أولا :- عرض تحليلى للخامات المستخدمه الطين ( Clay ) :- أو هيدرات سيلكات الالومنيوم وتتتج عن تحلل الصخور الناريه وتختلف انواعها تبعا للعمليات الجيولوجيه واماكن ترسبها (1) (1) , فسيلكات الالومنيوم هى الماده الاساسيه لجميع انواع الطينات مع وجود نسب متفاوته من الشوائب وكربونات الكالسيوم ومركبات الحديد مع تواجد الكوارتز والميكا والفلسبار (r) , ويمكن تصنيف الطين الى طينات اوليه منل الطين الصينى والبنتونيت ؛ أما الطينات الثانويه فهى التى نقلتها عوامل الطبيعه لاماكن اخرى فترسبت اما 
فى صورة طبقات افقيه وتحجرت مكونه صخور رسوبيه منل البولكلى والطفل الاحمر ؛ او هبطت تلك الصخور الرسوبيه فى باطن الارض لتصبح تحت تأثثر الضغط والحراره صخور متحوله مثل الطين الارضى الاحمر والطينات الحجريه

الطين الورقى ( Paper clay ) :- ويعرف احيانا بالطين الليفى , وهو أى نوع من الطينات المعالجه بألياف السيليولوز (ع) حيث تعتبر عجائن الورق الجاهز

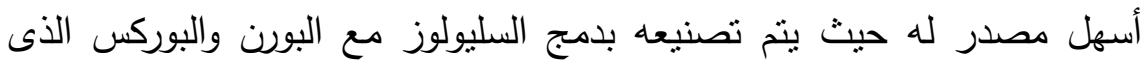

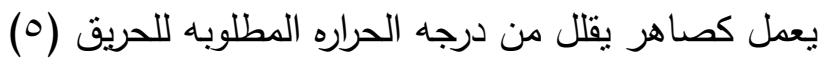

1- David Green - Pottery Materials and techniques - Queen Square - London - 1976 - P72

r- الفريد لوكاس - المواد والصناعات عند قدماء المصريين - ترجمة زكى اسكندر - دار الكتب 97 المصريه - القاهره - 9991 - 993

3- Frank and Janet Hammer- the Potter's dictionary - London -2012- P323

4- http://en.wikipedia.org/wiki/paperclay

5- www.Jerrybennett.net/paperclay.html

كما تعتبر خامات القطن النقى والكتان أحد المصادر الخام,وعامة يفضل اختيار الانواع ذات الالياف القصيره ليسهل دمجها بالطين وكلما زادت نسبة

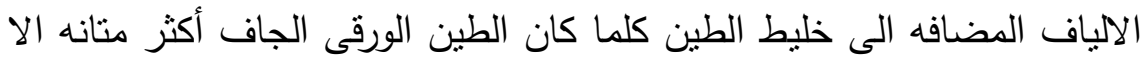
ان الكتله بعد الحريق تصبح بنيتها أضعف, لذا يوصى باستخدام نسبه لا تزيد

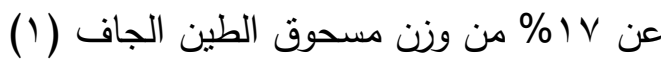

\section{الفيانس السيلكى ( Silica's faience) أو(طنت) بالهيروغليفية} tjehenet الفيانس السيلكى يعتبر أقرب المصطلحات العلميه والتىى وجد بتحليلها انها تحتوى على طبقتين مختلفتين فى نسبه العناصر المركبه لها وهى طبقه اللب , والسطح المزجج - ووجد نماذج المشكله منه بالعديد من الحضارات القديمه بمصر والعراق

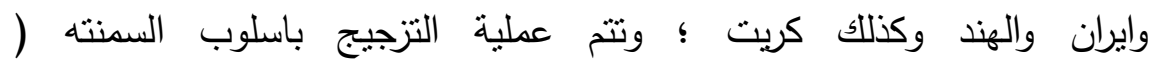


(Cementation انتاج الفاينس السيلكى عن التقنيات القديمه بنفس الاحجام الصغيره وانما ادخلت تعديلات لنسب الخلطات والاكاسيد الملونه واستخدام القوالب الجصيه كبديل عن

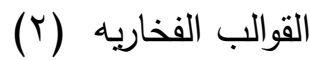
السيلكا ( Silicon dioxide ) وأهم مصادرها حجر الكوارتز النقى , الفلنت , الرمل ,وهى تتصهر وتتزجج فى درجة حراره • V) فى حالة عدم خلصها بأى

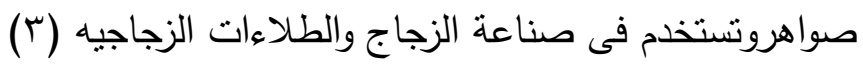

1-www.grahamhay.com.au/gartside1993.html

2-Kyoko, Yamahana- Ancient Egyptian Vitreous Material-Tokai universityjuly 2000

3- Frank and Janet Hammer- the Potter's dictionary - London -2012-p323 - القلسبار (Feldspar) أو حجر القمر والمسمى العلمى سيلكات الالومنيوم , وهو معدن يدخل فى تركيب العديد من الصخور الناريه ويستخدم فى خلطات الاجسام الخزفيه ليقلل من درجه تسوية الكاولين والكوارتز كما يقلل من الانكماش ويسهل عملية الجفاف (1) وينقسم لنوعين البلاجيوكليز و الارثوكليز (r)

كريونات الصوديوم (Sodium Carbonate) أو(Soda ash) وهو المصدر الرئيسى لآكسيد الصوديوم فى خلطات الطلاءات الزجاجيه وثانى مركبات الصوديوم استخداما بعد البوركس (r) السليولوز (Cellulose fiber) جزء اساسى فى جميع النباتات والاشجار , وله القدره على امتصاص الرطوبه (ع) التزهير (Efflorescence) تقنية تزجيح ذاتى تعتمد على نزوح الاملاح القلويه اثثاء عملية التجفيف فبتبر الماء حاملا معه السيكا والاكسيد الملون لسطح 
العمل مكونا طبقه مزججه منتظمه أثناء الحريق ويكون لون اللب وسطح الطبقه

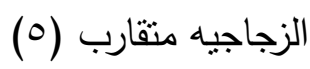

$$
\text { ا عبد الغنى الثال - الخزف ومصطلحاته الفنيه - مركز النشر بجامعة حلوان -1991 -ص }
$$

\section{2 www.Feldsparoutputin2005}

3 Frank and Janet Hammer- the Potter's dictionary - London -2012- p304 4 www.grahamhay.com.au/gartsde1993.html

5 Kyoko, Yamahana- Ancient Egyptian Vitreous Material-Tokai universityjuly 2000

\section{تمهيد}

قبل البدء فى عرض التجارب الخاصه والقياسات المعني بها البحث لا بد من شرح تفصيللى للطرق التى تم اتباعها فى تجهيز واعداد الجسم و تعتبر ثابته فى كافه انواع التجارب

\section{أ- تجعيز عجينة الورق}

ينت تقطيع الورق لقطع صغيره وتغمر فى حمام مائى ساخن لنحوحوالى ثلاث ساعات - تضرب فى خلاط كهربى حتى تتفتت تماما - تصفى من الماء الزائد بمصفاه معدنيه. ب-يخلط (مسحوق)مكونات الفيانس السيلكى جيدا بخلاط كهربى ما عدا (كربونات الصوديوم) (

ج - تضاف عحينة الورق المصفاه الى المسحوق الجاف وتمزج يدوبا د - يضاف نسبه كربونات الصوديوم الى با \% من وزن الخليط الجاف (ماء)؛ وبعد تمام ذوبانه بضاف الى باقى المكونات وبستمر عجن الخليط حتى تمام اندماجه ويمكن استخدامه فورا. هـ - تستخدم القوالب الجصيه فى استنساخ الاعمال حيث يمتص الماء الزائد ولا يستخرج العمل قبل ان يصل لمرحله اللدونه والا سيتعرض للالتواء 
و - العجائن الورقيه ساعدت على سرعه جفاف الاعمال وكذلك على تماسك الجسم بشكل اكبر وهو جاف ولم تؤثر على نزوح الاملاح الى السطح

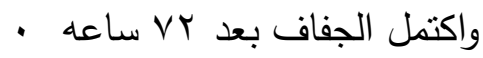
ز - تم الحرق فى فرن تجارب خزفى لمدة ثلاث ساعات ( تعليل لمدة ساعتين حتى درجة . .ـ درجه مئويه- الحرق لمدة ساعه حتى .90 درجه

$$
\text { مئويه) · مسعاعن }
$$

\section{-ثانيا :-اجراء تجارب لمكونات مختلفه}

تم اجراء تجارب بعد نثبيت نسبه مكون السيلكا ( كعنصر مزجج) وكربونات الصوديوم والكالسيوم (كصاهر قلوى) والاكسيد المعدنى ( كعنصر ملون ) , وتم اجراء ستة تجارب على ثلاث مجموعات لمربع م سم مستتسخه من قالب جصى واسطوانه مفرغه بارتفاع 0 سم مشكله بالضغط على اسطوانه ختشبيه الهجموعه الاولى تم اضافة كاولين - المجموعه الثانيه تم اضافة فلسبار صوديومى - المجموعه الثالثه نم اضافه بولكلى - ووجدة القياس بالجرام كما هو

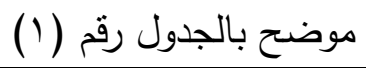

\begin{tabular}{|c|c|c|c|c|c|c|c|}
\hline اكسيد & كربونات & كربونات & سيلكا & بولكلى & كاولين & صوديومى & عينه \\
\hline 1. & & $r$. & 70 & & 90 & & 1 \\
\hline 1. & $r$. & & 70 & & 90 & & r \\
\hline 1. & & $r$. & 70 & & & 90 & r \\
\hline 1. & $r$. & & 70 & & & 90 & $\varepsilon$ \\
\hline 1. & & $r$. & 70 & 90 & & & 0 \\
\hline 1 & $r$. & & 70 & 90 & & & 7 \\
\hline
\end{tabular}

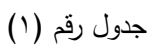

نتيجه التجارب ان العينه رقم (r) هى الوحيده التى تصلدت واكتمل تزجيجها كما هو موضح بالثكل رقم (1 أ - 1- ب ) ولم يحدث لآبعادها الطوليه والعرضيه انكماش كما لم يحدث ای اختلاف فى ارتفاع الاسطوانه المفرغه 


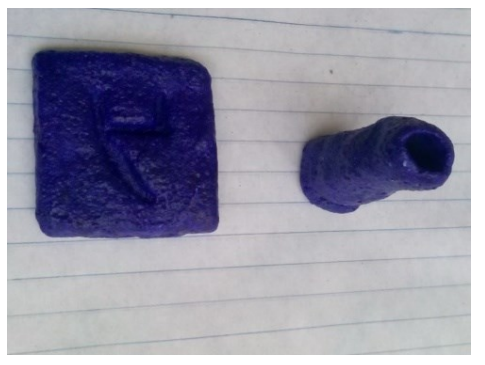

$$
\begin{aligned}
& \text { شكل رقم (1- ب ) } \\
& \text { العينه رقم بابعد انتهاء الحريق }
\end{aligned}
$$

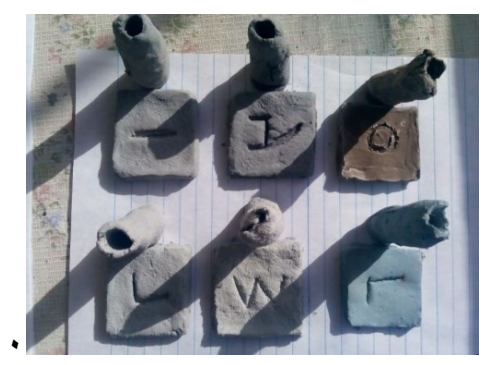

شكل رقم (1- (أ) العينات قبل الحرق والتسويه

ثالثا:-التعرف على الخصائص الميكانيكيه للقاينس السيلكى بعد اضافة العجائن الورقيه

تعرف علميا بقوى الاجهاد كالقابليه للضغط والالتواء للتعرف على مدى تحمل الكتله لنقل بعلوها ومدى قابليتها للانكماش او التشقق هوى التهاد

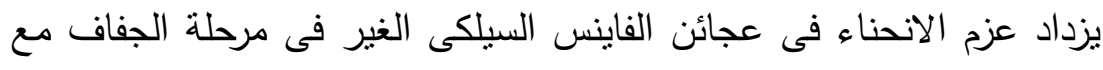
مقاومه لاجهاد الكسر مما يعطى امكانية تحمل المشغولات ذات حجم اكبر قياسا بالمشغولات التقليديه لعجائن الفيانس السيلكى التى عادتا ما تكون صغيره الحجم. تعتبر درجة الحريق من العوامل الهامه فى حاله التشكيل بسمك رقيق دون ظهور اى التواء ويجرى قياس الانحناء عند الحريق لدرجه حراره .90 فيتم رسم خط مستقيم بمقياس رسم ومنها ينم حساب الانحناء اثناء الحريق , وغالبا ما فاء يتصاعد دخان من لب الورق حتى درجة . مr مئويه لمدة تتراوح من • 1 : 10

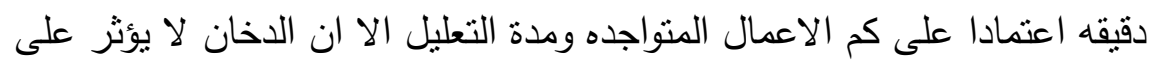

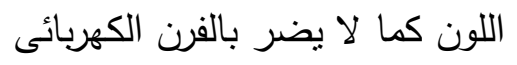


مع الحريق يمتلئ جسم العمل بالفراغات التى تركتها الالياف لتصبح نسبة

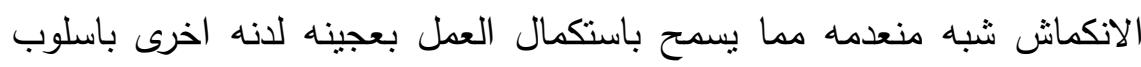
التطعيم او الاضافه , ولقد قامت الباحثه بتتفيذ تجربه عمليه على العينه رقم (r) باضافة عجينه لدنه بيضاء داخل التجويف الرقمى بالعينه وضغط البلاطه كامله داخل بلاطه من نفس العجينه البيضاء وكانت النتيجه الاندماج الكامل بين

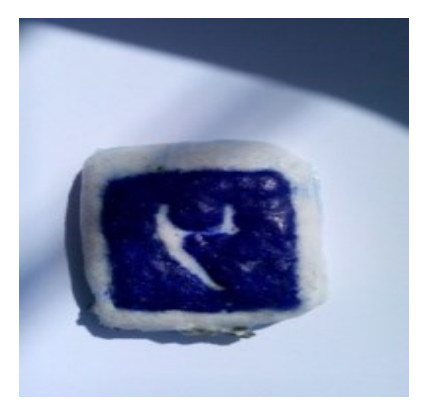

$$
\text { 90. النموذجين بعد الحريق والتسويه على درجة حراره }
$$

رابعا :- التعرف على اثر الاكاسيد الملونه

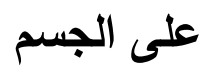

تم اضافة بعض الاكاسيد الملونه والصبغات الحراريه للعجائن بنسبة حوالى

\% من وزن الخلطه

\begin{tabular}{|c|c|}
\hline & \\
\hline & \\
\hline & \\
\hline
\end{tabular}



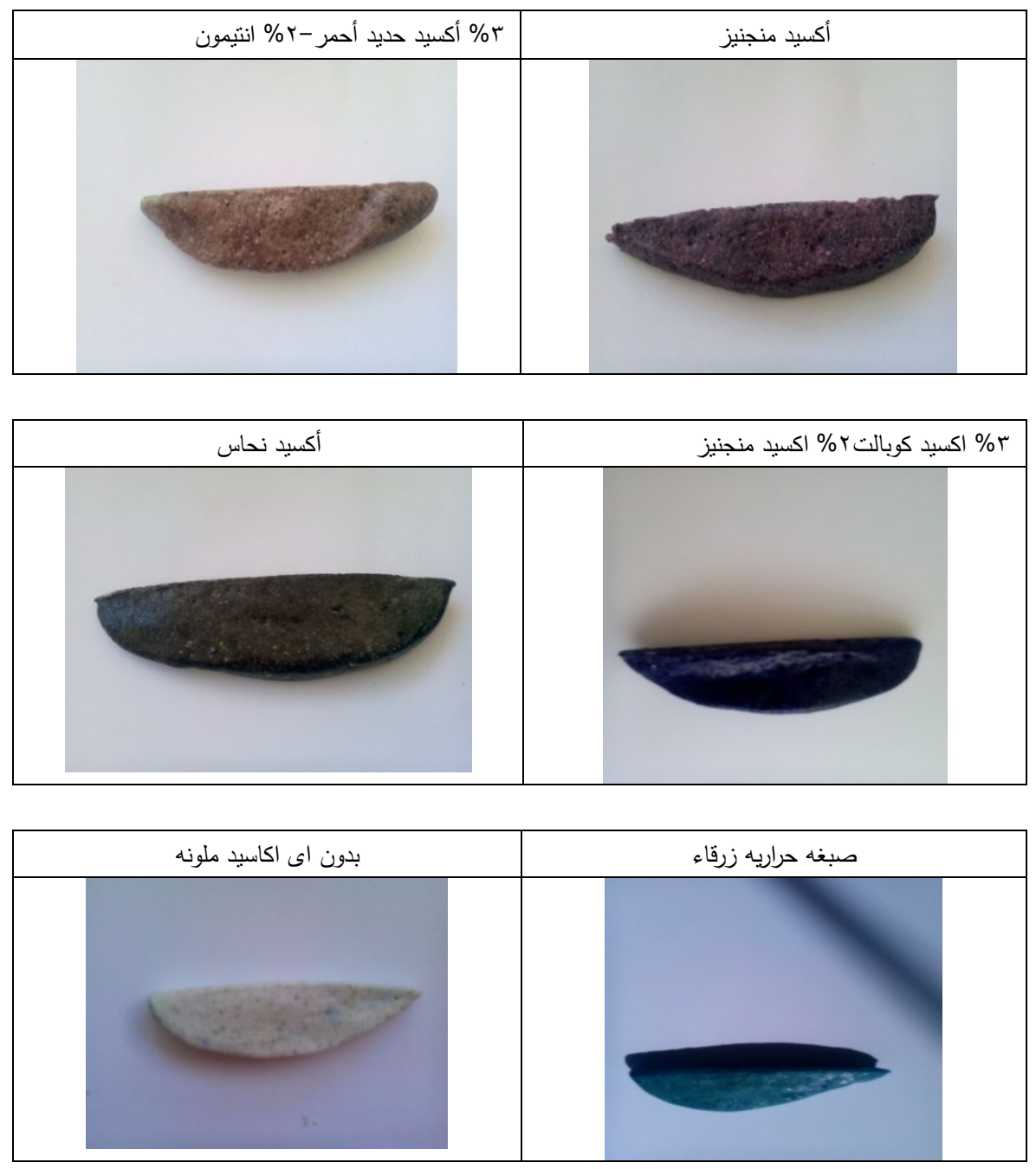

ترخيم للونين من العجائن

ترخيم للونين من العجائن 


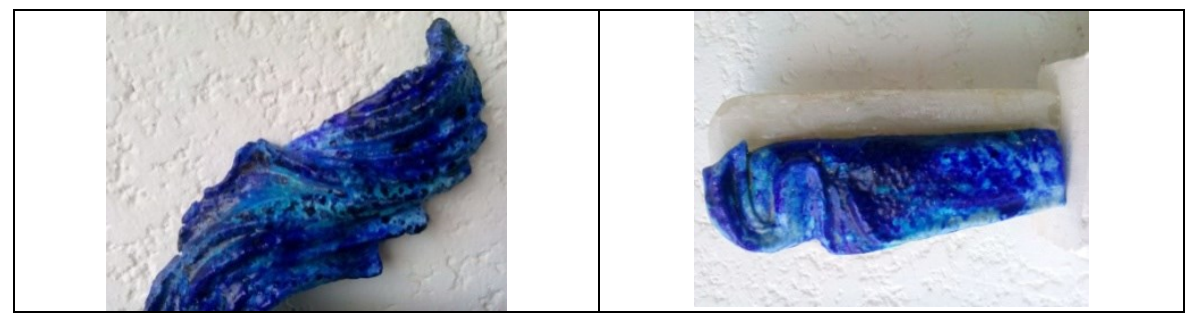

النتيجه من خلال التجارب السابقه للعينات تظهر وضوح الاثر اللونى اللامع على سطح العمل والذى تزداد كثافت بزيادة زمن التجفيف

كما اظهرت التجربه امكانيه استخدام تقنية الترخيم ما بين العجائن الملونه كذلك امكانية اضافه الصبغات الحراريه كملون حرارى للجسم وتكون اسهل من الاكسيد حيث لا تختلف درجتها اللونيه قبل الحريق عنها بعد الحرق والتسويه . خامسا :- تجربه تطبيقيه تظهر فيها امكانيات الخامه التشكيليه ومعطياتا الحماليه

قامت الباحثة بتتفيذ عدة اعمال كتطبيق عملى لمعرفة مدى امكانياتها فى التشكيل والحجم وسمك جدار العمل بتقنيات مختلفه فى التشكيل وتقنية الحريق 


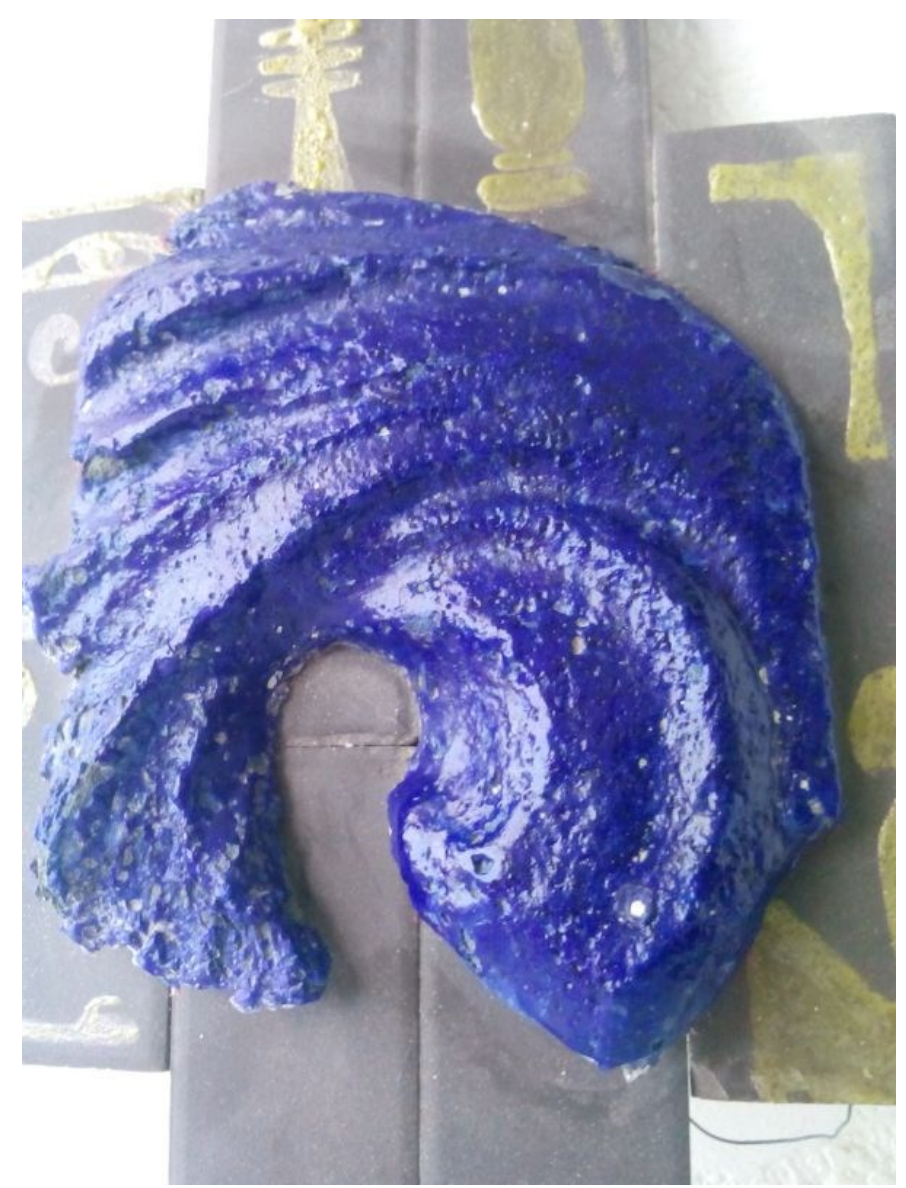

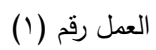

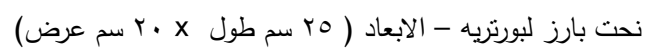

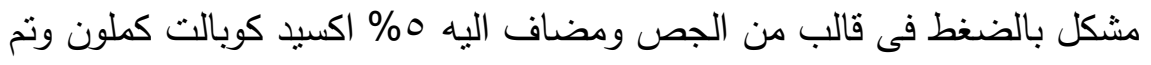
الحرق والتسوبه بفرن خزف كهربى ، 90 درجه مئوبه 


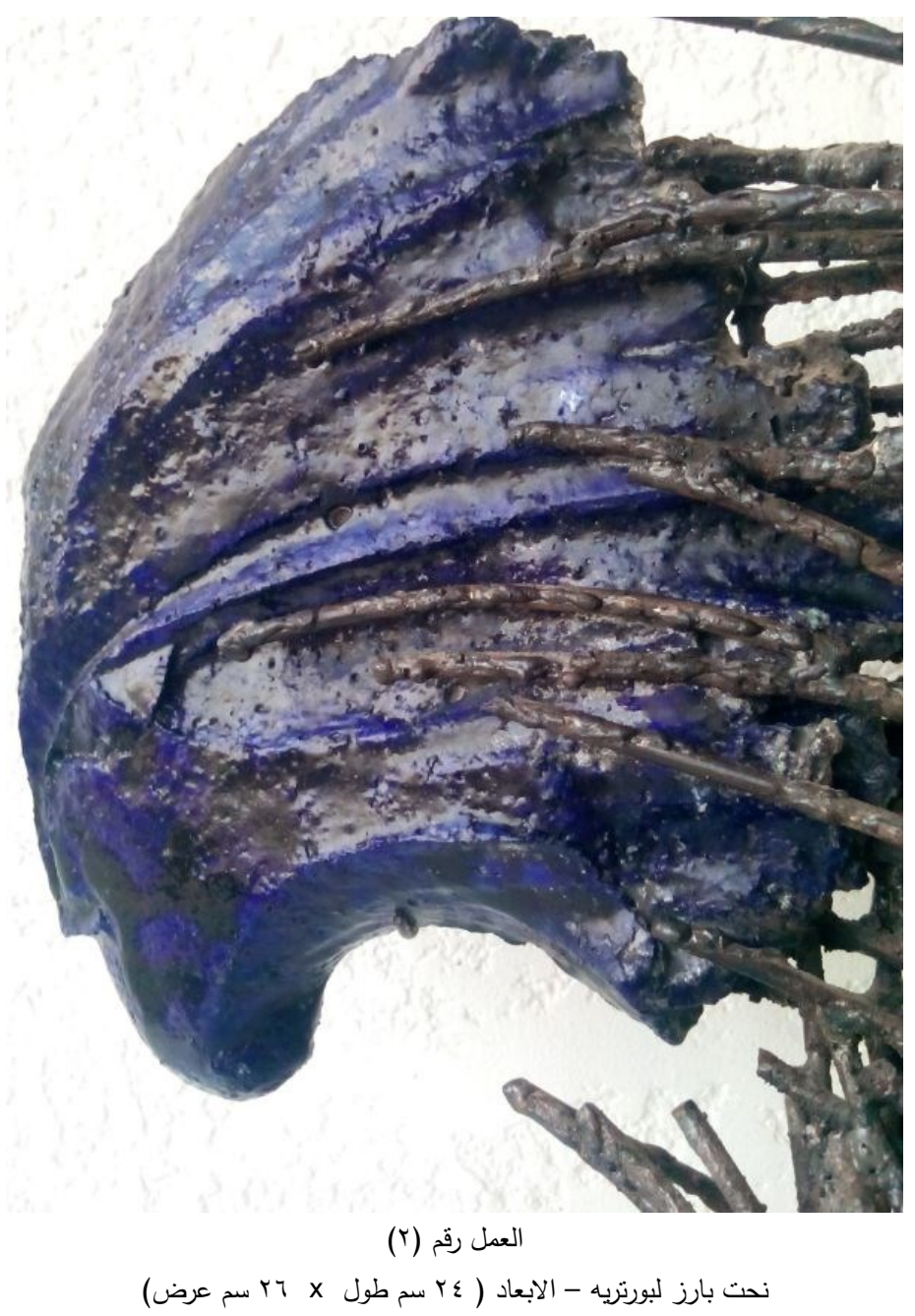

تشكيل مباشر من النحت البارز على مراحل مختلفه من الجفاف لمعرفة مدى التىرئ امكانية اضافة العجائن الى مسطحات جافه وبالفعل لم يحدث نتقق او التواء اثثاء الحريق ولكن ظر تفاوت فى درجة اللون على سطح العمل تم على حراره • 90 درج مئويه 


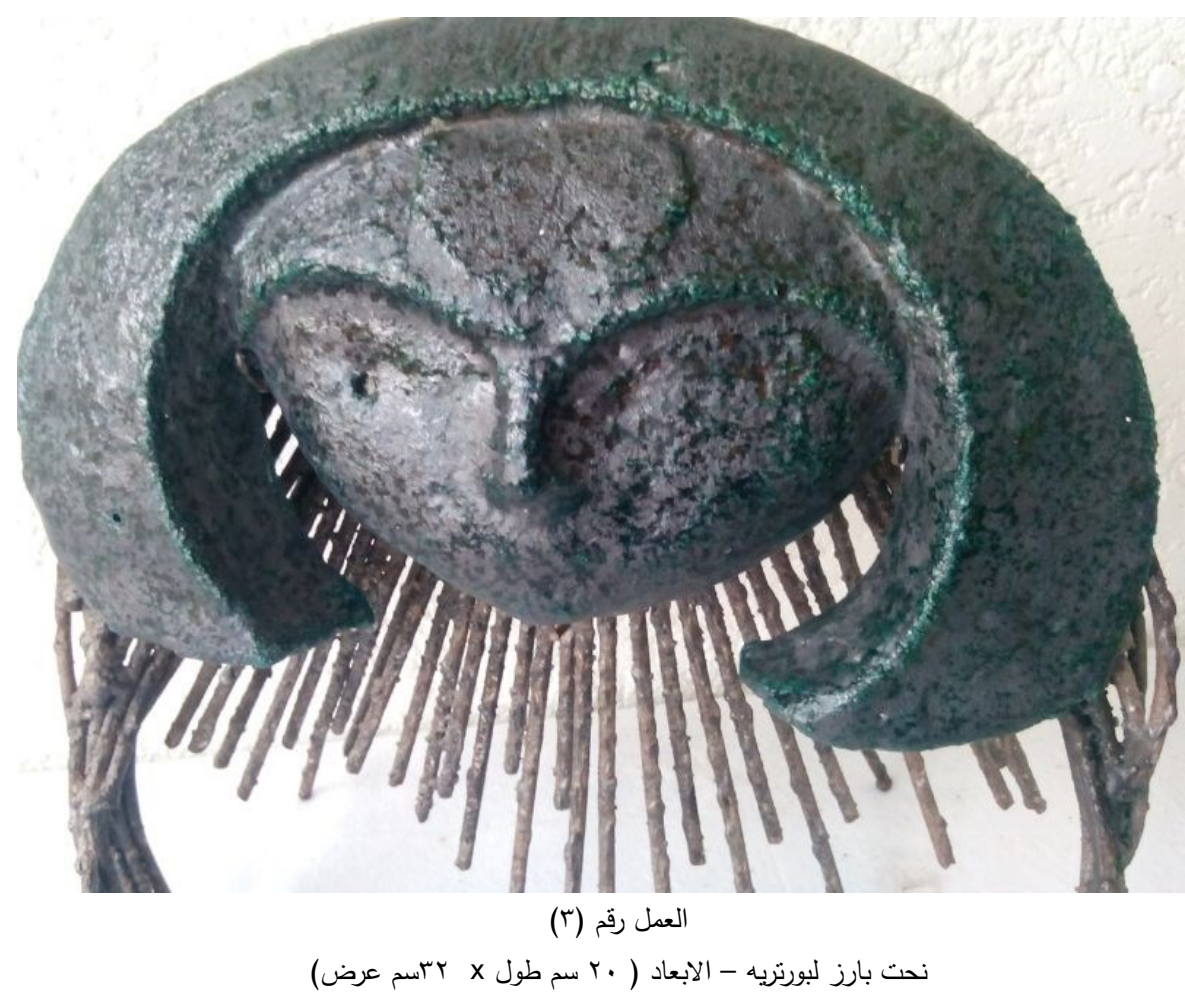

نحت بارز لبورتريه مضاف اليه ^\% من وزن الخلطه كربونات نحاس + r

ونم التشكيل بالضغط فى قالب جصى والحرق والتسويه لدرجه حراره . مئوبه 


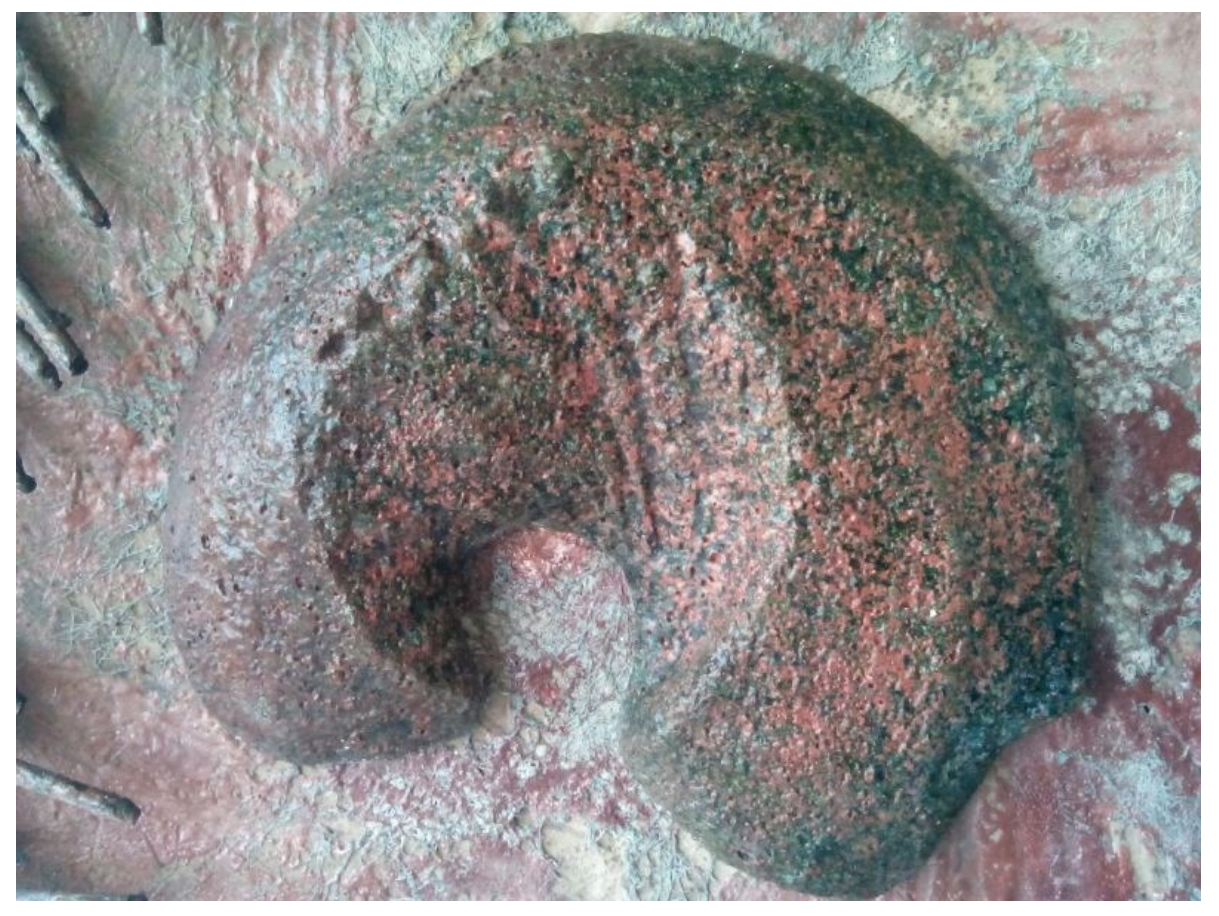

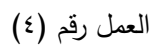

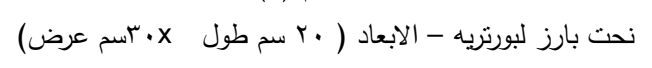

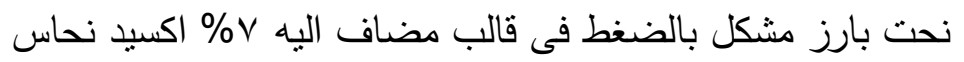

تم الحرق والتسويه بفرن غاز خزفى بتقنية حريق البريق المعدنى وتم اختزال السطح بواسطه مسحوق القلافونيه على درجة حراره . 70

الانتائجج

رغم جماليات الفيانس السيلكى ذاتى التزجيح الا انه لا يمكن تشكيله بأبعاد

كبيره الحجم لانه عند الجفاف يصبح هش سهل الكسر , كما انه يتم نشكيله فى قوالب ولا يمكن اضافة اى عجائن على السطح بعد تمام جفافه وفى حاله اعادة تلاينه يتم بالتبعيه اعادة تشكيله بالضغط فى القالب مره اخرى من خلال الدراسات والتجارب السابقه انتهينا لبعض النتائج الرئيسه لتحسين خصائص الفيانس السيلكى التقليدى فى مجال النحت الخزفى كما يلى 
- اضافة العجائن الورقيه للب الجسم تعتبر ماده ممتازه لتتكيل الاعمال الاكبر حجما فجزيئات السيلكا والفلسبار الصوديومى تتحد مع الألياف لهوبه لتكون شبكه داعمه للاعمال الجافه , كما انها تمنع التشقق والكسور فى لي حالة نقل الاعمال , وبعد الحريق يصبح الجسم مسامى فيزيد مقاومته للضغط والالتواء كما انها لا تؤثر على عملية التزهير او اللون النهائى للعمل - امكانية اعادة ترطيب عجائن الفيانس السيلكى اثثاء التشكيل واستكمال التشكيل المباشر على سطح العمل dry to ( اصبح فى الامكان لحام أجزاء العمل وهو فى الحاله الجافه ل

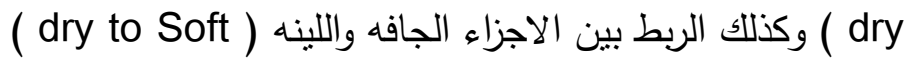
- امكن تحقيق متغير فى اللون الناتج عن الاكسيد المعدنى التى اختلفت باختلاف تقنية الحريق 


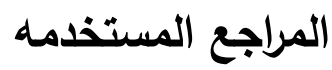

المراجع العربيه

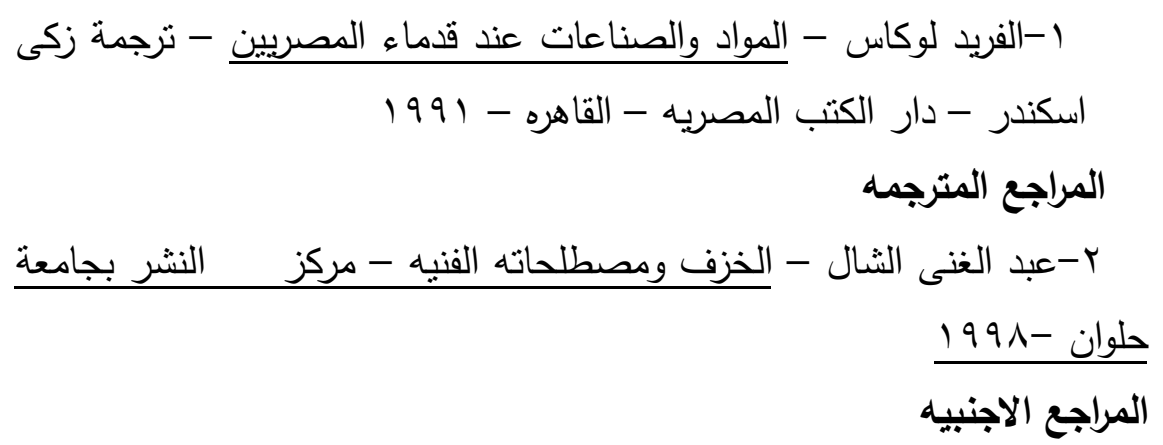

3-David Green - Pottery Materials and techniques -

Queen Square - London - 1976

4-Frank and Janet Hammer- the Potter's dictionary -

London -2012

5-Kyoko, Yamahana- Ancient Egyptian Vitreous

Material-Tokai university-july 2000

مواقع شبكة المعلومات

6-http://en.wikipedia.org/wiki/paperclay

7-http//Potery.about.com/od/deglazes/pt/testelay.htm

8-www.Jerrybennett.net/paperclay.html

9-www.grahamhay.com.au/gartside1993.html

10-www.Feldsparoutputin2005

11-www.grahamhay.com.au/gartsde1993.html 
الملخص

الفيانس السيلكى يعتبر من اقدم الخزفيات ذاتية التزجيج التى نم تشكيلها وانتاجهابكميات هائله من اقدم العصور؛ ولا يزال حتى يومنا هذا ينتج بنفس تقنيات التشكيل بالقوالب على احجام صغيره جدا مع تعديل وتغيير فى المركبات

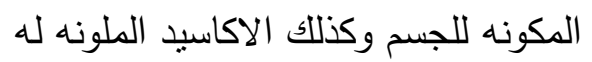

ومع تطور التجارب ومحاولة تحسين خواص الخامات الخزفيه وظهور الطينات الورقيه فى مجال النتكيل الخزفى ؛ بدأت دراسه الباحثه التى كان هدفها الرئيسى

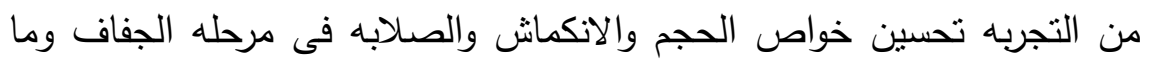
بعد الحريق لعجائن الفيانس السيلكى وذلك من خلال دراسات بحثيه محددهوالتى بدأت بعرض نظرى تحليلى للخامات المستخدمه واهم المصطلحات المستخدمه وند دراسة مقارنه من خلال اجراء تجارب على انواع مختلفه من المركبات للوصول الى افضل النماذج الصالحه للتشكيل ثم التعرف على الخصائص الميكانيكيه والتى تعرف علميا بقوى الاجهاد كالقابليه للضغط والالنواء للتعرف له

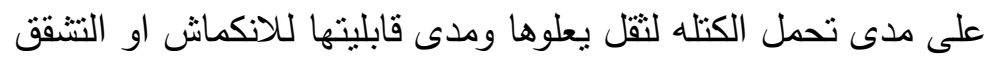

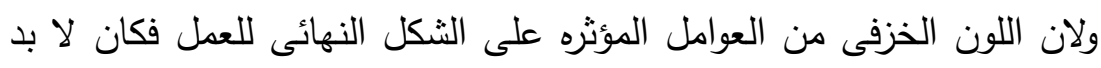
من التعرف على اثر الاكاسيد الملونه وظروف الحريق ونتائجه المباشره على الجسم واللون ؛ واخيرا تجربه تطبيقيه تظهر فيها امكانيات الخامه التشكيليه ومعطياتا الحماليه بتنفيذ عدة اعمال كتطبيق عمللى لمعرفة مدى امكانياتها فى التشكيل والحجم والسمك فى جدار العمل لئل 